\title{
Calidad microbiológica del aire de una unidad de preparados farmacéuticos estériles
}

\author{
Beatriz Caorsi P., Andrea Sakurada Z., M. Teresa Ulloa F., Marcela Pezzani V. y Paz Latorre O.
}

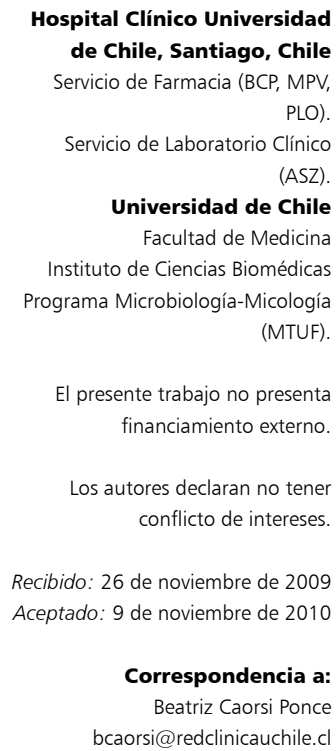

\section{Introducción}

$\mathrm{E}$ 1 aire presente en el interior de cualquier ambiente (hospitales, escuelas, casas, etc) contiene una carga microbiana que es aportada en gran parte, por las personas que están presentes en estos sitios, el tipo de actividades que ellas realizan, el grado de capacitación que posean, su actitud y hábitos personales ${ }^{1-5}$. También influyen el programa de aseo y mantención del área y la rigurosidad en su cumplimiento, el aire exterior, el polvo ambiental, el tipo de suelo, además de la temperatura, la ventilación, la humedad, el recambio de aire y la presencia cercana de volúmenes de agua estancados o en movimiento ${ }^{1,2,6}$.

En la elaboración de preparados farmacéuticos estériles es necesario garantizar productos de una elevada calidad microbiológica que no posean contaminación por microorganismos presentes en el aire del área de producción, por lo cual es necesario disponer de áreas limpias. En dichas áreas se busca cumplir con los controles internacionales que pretenden minimizar los riesgos de contaminación microbiana ${ }^{1-3}$.

La norma para la producción de preparados farmacéuticos estériles contempla el control microbiológico ambiental, tanto del aire como de las superficies en distintos puntos, establece un recuento bacteriano aceptable expresado en unidades formadoras de colonias (ufc), según las áreas de trabajo (sitios) y en situación de reposo ${ }^{3,4}$. Para esta norma existen diversas clasificaciones, tal como se indica en la Tabla 1.

Tanto la norma de medicamentos de la Unión Europea (GMP) como el estándar de la United States Pharmacopeia (USP $209 \mathrm{E}$ ) presentan equivalencia entre sí y con la norma internacional ISO14644-1 (Tabla 1).

La GMP clasifica las zonas limpias en grados que establecen parámetros de la calidad microbiológica del aire ${ }^{3,4}$.

- Zona A: Zona específica para operaciones de alto riesgo como por ejemplo, llenado, bandejas de tapones, ampollas, viales abiertos y realización de conexiones asépticas. Estas condiciones se consiguen normalmente en cabinas de flujo laminar. Estos sistemas deben proporcionar una velocidad homogénea del aire de $0,45 \mathrm{~m} / \mathrm{s} \pm 20 \%$ en el punto de trabajo. El límite de microorganismos es $<1 \mathrm{ufc} / \mathrm{m}^{3}$ de aire según $\mathrm{GMP}^{4}$ y $3 \mathrm{ufc} / \mathrm{m}^{3}$ según USP $209 \mathrm{E}^{3}$.

- Zona B: Entorno para la zona de grado A en el caso de preparación y llenado aséptico. El límite de microorganismos por $\mathrm{m}^{3}$ de aire es 10 ufc según $\mathrm{GMP}^{4}$ y 3 ufc según USP $209 \mathrm{E}^{3}$.

- Zona Cy D: Zonas limpias para realizar fases menos críticas de la fabricación de medicamentos estériles. Los límites de microorganismos por $\mathrm{m}^{3}$ de aire para ambas zonas son $100, \mathrm{ufc} / \mathrm{m}^{3}$ y $200 \mathrm{ufc} / \mathrm{m}^{3}$ según $\mathrm{GMP}^{4}$ y 20 y 100 ufc $/ \mathrm{m}^{3}$ según USP 209 E, respectivamente ${ }^{3}$. 
Un programa de monitoreo ambiental microbiológico permite además establecer el nivel de alerta, considerado como aquel recuento que nos indica una variación leve al alza que, de no ser corregida, se puede convertir en una tendencia a valores inusualmente altos y/o fuera del rango. Exceder el nivel de alerta no necesariamente requiere una acción correctora definitiva; no obstante, debe provocar a lo menos una investigación de seguimiento que podría incluir modificaciones en el plan de muestreo. En cambio, el nivel de acción es aquel nivel de microorganismos que siendo excedido, requiere una investigación inmediata, seguido de una acción correctora.

En nuestra búsqueda, no encontramos información en Chile sobre la calidad microbiológica del aire en las unidades de preparados estériles de farmacia.

El objetivo de este trabajo fue evaluar la calidad bacteriológica del aire de la Unidad de Preparados Farmacéuticos Estériles del Servicio de Farmacia del Hospital Clínico de la Universidad de Chile determinando los niveles de contaminación de cada área de la unidad, los que fueron comparados con los niveles establecidos internacionalmente, para implementar las normas vigentes de control microbiológico de área limpia y establecer niveles de alerta y acción.

\section{Materiales y Métodos}

Se efectuó un estudio en la Unidad de Preparados Farmacéuticos Estériles del Servicio de Farmacia (UPFE) del Hospital Clínico de la Universidad de Chile, en la que se realizó un monitoreo permanente a través de controles microbiológicos periódicos. Éstos se realizaron diariamente, durante los meses de enero y febrero de 2005 y con frecuencia bisemanal desde junio de 2005 hasta febrero de 2006. En el estudio se establecieron ocho sitios de control: Zona A: corresponde al área de preparación de preparados estériles: Sitio 1: cámara de flujo laminar grande; sitio 2: cámara de flujo laminar pequeña; sitio 3: mesón lateral derecho área de preparación. Área de transición: sitio 4: zona de transferencia. Zona C: corresponde al área de vestuario: sitio 5. Zona D: corresponde al área de preparación de material: sitio 6: mesón lateral izquierdo; sitio 7: mesón lateral derecho; Sitio 8: mesón costado (Figura 1).

La recolección de muestras de aire se realizó mediante la técnica de impacto en placa ${ }^{3}$, en cada uno de los ocho sitios que se muestran en la Figura 1, utilizando un equipo MAS-100 de Merck ${ }^{\circledR}$. En este equipo se colocó una placa Petri irradiada con agar soya triptosa (BioMerieux ${ }^{\circledR}$ ), sobre la cual el equipo impactó 100 litros de aire por minuto con una velocidad del aire de 0,45 metros/segundo, Las placas se retiraron del equipo por el personal de la UPFE y fueron enviadas al laboratorio, en el que fueron incubadas

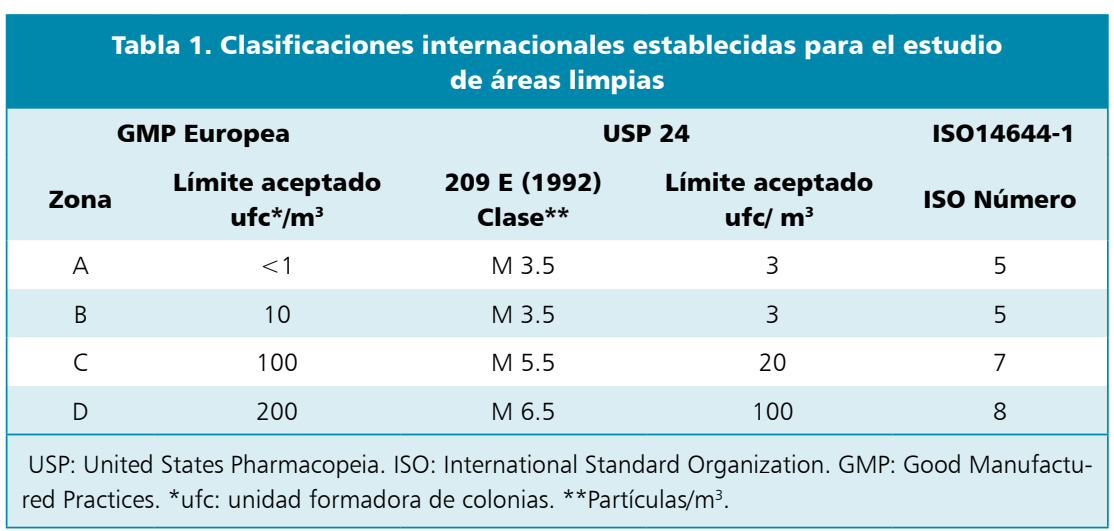

a $34^{\circ} \mathrm{C}$ por 72 horas. Posteriormente, se realizó el recuento de colonias bacterianas obtenidas en cada placa en cada uno de los ocho sitios enumerados del 1 al 8 .

A su vez, se realizó la identificación bacteriana a la totalidad de las colonias obtenidas de los sitios 1 al 5, por ser éstos los que representan el mayor riesgo de contaminación. Ésta se realizó en base a normas internacionalmente aceptadas ${ }^{7}$ que incluyeron: observación de la morfología de la colonia, producción de pigmento, hemólisis, tinción de Gram; en el caso de cocáceas grampositivas, pruebas de la catalasa, novobiocina, bacitracina, y oxidasa en el caso de bacilos gramnegativos. En la identificación de género y especie se utilizó el sistema de galerías de identificación de BBL Crystal Becton-Dickinson ${ }^{\circledR}$, tanto para enterobacterias, bacilos gramnegativos no fermentadores como cocáceas grampositivas.

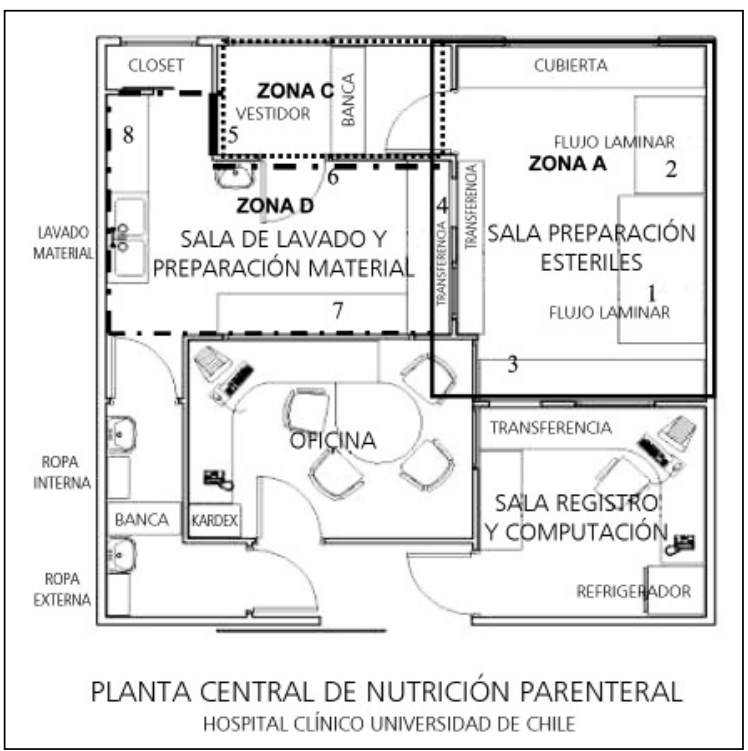

Figura 1. Plano de unidad de preparados estériles en el cual se indican los puntos de muestreo. 


\begin{tabular}{|c|c|c|c|c|c|c|c|c|c|c|c|c|}
\hline Área & $\begin{array}{c}\text { Ene } \\
05\end{array}$ & $\begin{array}{c}\text { Feb } \\
05\end{array}$ & $\begin{array}{l}\text { Jun } \\
05\end{array}$ & $\begin{array}{l}\text { Jul } \\
05\end{array}$ & $\begin{array}{l}\text { Ago } \\
05\end{array}$ & $\begin{array}{c}\text { Sep } \\
05\end{array}$ & $\begin{array}{l}\text { Oct } \\
05\end{array}$ & $\begin{array}{c}\text { Nov } \\
05\end{array}$ & $\begin{array}{l}\text { Dic } \\
05\end{array}$ & $\begin{array}{c}\text { Ene } \\
06\end{array}$ & $\begin{array}{c}\text { Feb } \\
06\end{array}$ & $\begin{array}{l}\text { Límite aceptado } \\
\text { ufc }^{*}\end{array}$ \\
\hline \multicolumn{13}{|l|}{ ZONA A: Área de preparación } \\
\hline Sitio 1 & $0-0$ & $0-0$ & $0-0$ & 0 & 0 & 0 & 0 & 0 & 0 & 0 & 0 & 3 \\
\hline Sitio 2 & 0 & 0 & 0,1 & 0 & 0 & 0 & 0 & 0 & 0 & 0 & 0 & 3 \\
\hline Sitio 3 & $0-4$ & $0-7$ & $1-6$ & $0-3$ & $0-5$ & $0-3$ & $0-2$ & $0-5$ & $0-2$ & $0-2$ & $0-4$ & 3 \\
\hline Sitio $4 * *$ & $0-5$ & $0-2$ & $0-21$ & $0-2$ & $0-1$ & $0-2$ & $0-3$ & $0-4$ & $0-2$ & $0-3$ & $0-3$ & $3^{* *}$ \\
\hline \multicolumn{13}{|l|}{ ZONA C: Área de vestuario } \\
\hline Sitio 5: Repisa vestuario & $0-6$ & $0-6$ & 0.5 & $0-3$ & $0-5$ & $0-4$ & $0-2$ & $0-7$ & $0-11$ & $0-3$ & $1-7$ & 20 \\
\hline \multicolumn{13}{|l|}{ ZONA D: Área de material } \\
\hline Sitio 6: Mesón 1 área lavado & $0-21$ & $1-39$ & $2-60$ & $1-13$ & $1-37$ & $2-12$ & $2-5$ & $3-12$ & $2-12$ & $3-36$ & $1-53$ & 100 \\
\hline Sitio 7: Mesón 2 área lavado & $1-13$ & $0-32$ & $3-46$ & $2-14$ & $3-41$ & $1-9$ & $2-9$ & $1-33$ & $4-6$ & $3-14$ & $1-54$ & 100 \\
\hline Sitio 8: área lavado lavadero & $1-10$ & $0-60$ & $0-15$ & $1-10$ & $1-30$ & $3-12$ & $2-7$ & $3-50$ & $2-5$ & $3-15$ & $3-55$ & 100 \\
\hline
\end{tabular}

Determinación de niveles de alerta: Para cada sitio se sumaron los recuentos y se obtuvo un promedio, se calculó la diferencia entre el promedio y el valor permitido. A esta diferencia se le calculó el $80 \%$ siendo éste el valor definido como el valor de alerta válido para esta área del laboratorio. Nivel de acción corresponde al límite aceptado internacionalmente; en nuestro estudio usamos los valores indicados por la USP.

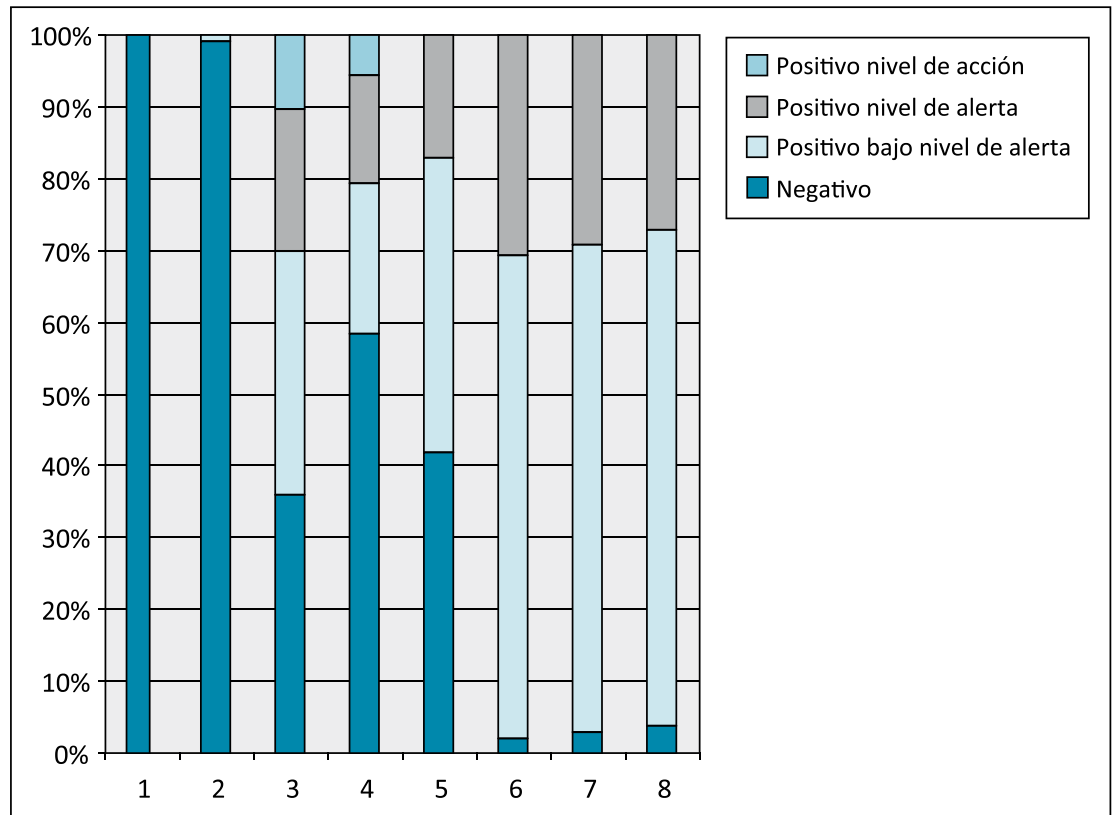

Figura 2. Distribución de los valores de los recuentos bacterianos de los diversos sitios.

\section{Resultados}

La calidad microbiológica de los ocho puntos de muestreo y los niveles de alerta y de acción correspondientes a las zonas A, C y D se evaluaron determinando el recuento bacteriano y la identificación de cada colonia aislada de los sitios 1 al 5 (Zona A y C).

Se estudiaron 839 muestras, de las cuales 474 (56,5\%) resultaron positivas, variando los porcentajes de positividad en los distintos meses, entre 51,3 y $67 \%$ con un promedio de $57,2 \%$. Los resultados para cada área se interpretaron según el Estándar Federal 209 E de la USP.

Los valores descritos en la Tabla 2 muestran los rangos de recuento bacteriano según el sitio, durante cada mes del período de estudio.

Zona A: En esta zona se observó que prácticamente la totalidad de las muestras obtenidas de $\operatorname{los}$ sitios 1 y 2 , que corresponden al área de preparación de preparados estériles $(211 / 212)$ fueron negativas. Sólo una fue positiva, pero bajo los límites permitidos. El sitio 3 presentó la mayor variación en los recuentos con 11/106 (9,4\%), valores superiores a los límites permitidos (Figura 2, Tabla 2). En el sitio 4 (sitio de transferencia), 6/106 muestras presentaron valores superiores a los permitidos. Esta zona no tiene un valor de límite aceptado internacionalmente pero, para efectos de este trabajo, aplicamos el límite establecido para la Zona A debido a que su ubicación fue considerada estratégica. Los valores de alerta para estos sitios fueron: sitios 1 y 2: 0 ufc, sitios 3 y 4: 1 ufc.

Zona C: Esta zona corresponde al sitio de vestuario. Los recuentos fluctuaron entre 2 y 11 ufc con un prome- 
dio de 5 ufc, lo cual indica valores muy por debajo del límite permitido de 20 ufc (Tabla 2, Figura 2). En total se tomaron 105 muestras, sólo una muestra tuvo recuento sobre el nivel de acción. El valor de alerta para el sitio 5 fue de 2 ufc.

Zona D: Área de material, esta zona corresponde a los sitios 6 (mesón 1), sitio 7 (mesón 2) y sitio 8 (lavadero), todos dentro del área de lavado. Las tres áreas presentaron desarrollo microbiano, con $66 \%$ de positividad bajo nivel de alerta, 29\% de positividad en nivel de alerta y $1,3 \%$ en rango de acción, aunque muy por debajo del límite aceptado. (Tabla 2). El valor de alerta para los sitios 6, 7 y 8 fue de 8 ufc. En esta zona no se realizó identificación microbiológica de los aislados.

Los resultados de los recuentos categorizados en base a los niveles de alerta y de acción se muestran en la Figura 2.

En general, con respecto al tipo de bacterias aisladas en las zonas A y $\mathrm{C}$, se observó un gran predominio de bacterias grampositivas $(95,9 \%)$, por sobre las gramnegativas $(4,1 \%)$. Tres de los géneros bacterianos más prevalentes, Staphylococcus coagulasa negativa, Micrococcus spp y Corynebacterium spp $(80,6 \%)$, son de origen humano pues forman parte de la microbiota de la piel. Sólo 11,8\%, representado por especies de Bacillus spp, fue considerado como microbiota ambiental (Tabla 3).

\section{Discusión}

En la elaboración de preparados farmacéuticos estériles es necesario garantizar productos de una elevada calidad microbiológica que no posean contaminación por microorganismos presentes en el aire de la zona de producción, por lo cual es necesario disponer de áreas limpias ${ }^{1,3,6}$. En dichas áreas se debe cumplir con los controles internacionales que pretenden minimizar al máximo los riesgos de contaminación microbiana. Para cumplir este objetivo se realizan controles por métodos físicos y/o químicos que son validados y medidos en su eficacia por métodos microbiológicos $1,3,4,8,9$.

Existen varias técnicas para estudiar muestras de aire, nosotros elegimos el impacto en placa porque es cualitativa y cuantitativamente la más precisa, permitiendo además del recuento bacteriano, la identificación de las colonias obtenidas. El equipo utilizado (MAS-100 de Merck®) es portátil, de fácil manejo y se puede localizar con facilidad en cada uno de los sitios a muestrear; es el método recomendado por la Food and Drug Administration (FDA) de EUA para este tipo de estudios ${ }^{8,9}$. En este método, los microorganismos se separan de la corriente de aire utilizando la inercia para forzar la sedimentación sobre la placa de Petri ${ }^{1,3}$.

Los resultados obtenidos nos han permitido establecer que la calidad microbiológica del aire dentro de la unidad
Tabla 3. Género y/o especies bacterianas aisladas de los sitios Zonas A y C

\begin{tabular}{lcccc|} 
Género y/o Especie bacteriana & $\begin{array}{c}\text { n cepas } \\
\text { total }\end{array}$ & $\begin{array}{c}\text { \% } \\
\text { total }\end{array}$ & $\begin{array}{c}\text { Zona A } \\
\text { Sitio 1-4 } \\
\mathbf{( \% )}\end{array}$ & $\begin{array}{c}\text { Zona C } \\
\text { Sitio 5 } \\
\mathbf{( \% )}\end{array}$ \\
Staphylococcus coagulasa negativa & 109 & 41,44 & $59(54,2)$ & $50(45,8)$ \\
Micrococcus spp & 81 & 30,79 & $40(49,4)$ & $41(50,6)$ \\
Bacillus spp & 31 & 11,78 & $16(51,6)$ & $15(48,4)$ \\
Corynebacterium spp & 22 & 8,46 & $9(40,9)$ & $13(59,1)$ \\
Staphylococcus aureus & 8 & 3,04 & $6(75)$ & $2(25)$ \\
Streptococcus salivarium & 1 & 0,38 & $1(100)$ & 0 \\
Acinetobacter /woffi & 3 & 1,14 & $2(66,6)$ & $1(33)$ \\
Pantoea agglomerans & 2 & 0,76 & $1(50)$ & $1(50)$ \\
Sphingomonas paucimobilis & 1 & 0,38 & $1(100)$ & 0 \\
\hline Cryseobacterium indologenes & 1 & 0,38 & $1(100)$ & 0 \\
\hline Brevundimonas vesicularis & 2 & 0,76 & $2(100)$ & 0 \\
\hline Empedobacter brevis & 1 & 0,38 & $1(100)$ & 0 \\
\hline Enterobacter sakazakii & 1 & 0,38 & $1(100)$ & 0 \\
\hline Total & 263 & 100 & 140 & 123 \\
\hline
\end{tabular}

estudiada se encuentra dentro de los estándares internacionalmente permitidos ya que se obtuvo $364(43,5 \%)$ muestras con cultivos negativos y en aquellas muestras con resultados positivos $(56,2 \%)$; la mayoría de los valores de recuento microbiano encontrados estuvieron muy por debajo de los rangos permitidos internacionalmente.

En la zona A, el sitio de mayor variabilidad en el recuento promedio mensual y que presentó el mayor porcentaje de lecturas en el nivel de alerta y de acción fue el sitio 3 (mesón lateral derecho del área de preparación). Cabe destacar que esta situación no influyó en el resto de los sitios del área de preparación, específicamente los sitios 1 y 2 donde se realizan los procedimientos, por lo que representan los sitios de mayor riesgo dentro de la unidad. Estos sitios permanecieron negativos en sus resultados microbiológicos, salvo en una de las 212 muestras analizadas pero con un valor bajo la norma. Una posible explicación para esta mayor carga bacteriana en el sitio 3 pudiera estar relacionada con la distribución no uniforme del aire, dado que en algunas situaciones se producen zonas neutras con distinta circulación de éste.

De la totalidad de las cepas aisladas la gran mayoría correspondió a géneros grampositivos de la microbiota humana, Staphylococcus coagulasa negativa Micrococcus spp y Corynebacterium spp, y en menor cantidad, del aire y del suelo, especialmente Bacillus spp. El resto de las bacterias aisladas representan un porcentaje muy bajo en este estudio, en concordancia con lo reportado por la FDA 
y otros trabajos publicados en el extranjero, en los cuales aproximadamente $80 \%$ es aportado por los seres huma$\operatorname{nos}^{1-3,7}$. Las especies de Bacillus son microorganismos esporulados aportados por el suelo, altamente resistentes al ambiente y pese a esto tienen baja presencia, lo que se explica por las medidas de control que se toman dentro un área limpia; las otras especies bacteriana encontradas representan un porcentaje mínimo.

Las acciones a tomar consideraron el recuento de cada sitio, la tendencia de estos valores y la identificación y tipo de bacterias que conformaron la carga bacteriana (ambientales y/o microbiota). Cuando se observa un aumento en los valores de los recuentos de uno o varios de los sitios, se deben revisar los parámetros de temperatura y humedad. Si el aumento de la carga bacteriana está dado principalmente por bacterias ambientales, se analiza el cumplimiento del programa de aseo y se puede contemplar un reforzamiento al grupo de operadores del área. Si este aumento se relaciona con bacterias de la microbiota humana, se deben reforzar hábitos de aseo personal y observar destrezas y tiempos en que se desarrollan los procedimientos. Se debe evaluar si existe una circulación de personas mayor de lo normado o que no son los titulares para dichas funciones (vacaciones, licencias etc). Durante nuestro estudio, siempre obtuvimos respuestas eficientes y rápidas ante dichas medidas. Si no se logran corregir los valores en un tiempo adecuado, es imperioso revisar el estado de los filtros y descartar una falla estructural del área.

La implementación del programa de monitoreo microbiológico ambiental en nuestra unidad de elaboración de preparados farmacéuticos estériles nos ha permitido implementar un control microbiológico permanente sobre un área limpia, según indican las normas internacionales, para obtener las mejores condiciones y las menos riesgosas para los pacientes que requieran los servicios de la UPFE del Servicio de Farmacia.

Establecer nuestros niveles de alerta y de acción ajustados a nuestra condición institucional y la identificación de los bacterias obtenidas en las áreas más sensibles de la unidad, nos permitirá detectar y conocer el origen de la carga bacteriana y su implicancia en elaborar las medidas de corrección y o los puntos a intervenir., ${ }^{1,3}$.
Agradecimientos. A las siguientes personas por su opinión técnica sobre el tema y por el apoyo computacional: M. Ángeles Mosso, M. Eugenia Pinto, Iván Solís, Alberto Fica, Lorena Brito, Rafael Pineda, Chantal Urrutia, Nora Silva y Nancy Abusada.

\section{Resumen}

Introducción: La elaboración de preparados farmacéuticos estériles requiere áreas limpias que deben cumplir estándares internacionales para minimizar la contaminación microbiana. Objetivo: Evaluar la calidad bacteriológica del aire de la Unidad de Preparados Farmacéuticos Estériles del Servicio de Farmacia del Hospital Clínico de la Universidad de Chile y establecer niveles de alerta y acción. Material y Métodos: Se monitorearon ocho puntos representativos de la unidad, diariamente entre enero y febrero de 2005 y bisemanalmente de junio a febrero de 2006. Se estudiaron 839 muestras de aire, recolectadas mediante el método de impacto en placa (equipo MAS-100). Resultados: De las muestras estudiadas, $474(56,5 \%)$ fueron positivas; de éstas, sólo $17(3,5 \%)$ estuvieron fuera del rango permitido, porcentaje que representa el $2 \%$ del total. Las muestras de los sitios 1 y 2 (flujo laminar grande y pequeño), que corresponden al área de preparación de preparados estériles fueron negativas. Los sitios 3 (mesón) y 4 (transfer) presentaron ocasionalmente valores superiores a los límites. Los microorganismos más frecuentes fueron Staphylococcus coagulasa negativa, Micrococcus spp y Corynebacterium spp, agentes de la microbiota de la piel y, menor porcentaje, Bacillus spp, agente de la microbiota ambiental. Conclusiones: Desde el punto de vista microbiológico, la calidad del aire de la zona de preparaciones estériles descrita presenta niveles ajustados a estándares internacionales. El establecer niveles de alerta y acción institucionales y la identificación de los microorganismos obtenidos en las áreas más sensibles de la unidad permite cuantificar la carga microbiana y conocer sus componentes para determinar las intervenciones a realizar cuando ellas estén indicadas.

\section{Referencias}

1.- De La Rosa M del C, Ullán C, Prieto M del $\mathrm{P}$, Mosso $\mathrm{M}$ de los A. Calidad microbiológica del aire de una zona limpia en una industria farmacéutica. Anal Real Acad Farm 2000; 66: 213-28.

2.- De La Rosa M del C, Mosso M de los A, Ullán C. El aire: hábitat y medio de transmisión de microorganismos. Observatorio Medio ambiental 2002; Col 5: 375-402.

3.- Sterile Drug Products for Home Use/ General
Information. United States Pharmacopoeia 24. $2134-9$.

4.- Beaney M Alison. Quality Assurance of Aseptic Preparation Services. Third Edition 2001. Londres, Pharmaceutical Press, 2001, págs 1-89.

5.- $\quad$ Sizer T, Duncombe R, Needle R, Sewell G. Universal Operator Broth Transfer Validation. National CIVAS Group, abril 2005 P 1-7.

6.- Rosa C, Sánchez C, Ullan C, Mosso A. Microbiota fúngica del ambiente de una zona limpia de envasado de materias primas farmacéuticas. Revista Científica Colegio
Oficial de Farmacéuticos de Madrid. N11, Nov 2002. p. 38-42.

7.- Murray P, Baron E, Jorgensen J, Pfaller M, Yolken R. In Manual of Clinical Microbiology. 8th edition, ASM press WD CW. 2003.

8.- Mark Hallworth. Particle Monitoring Requirements in Pharmaceutical Cleanrooms. March 2005, App 41 Page 7 of 7. www.pmeasuring.com.

9.- Food and Drug Administration's (FDA) Guidance for Industry Sterile Drug Products Produced by Aseptic Processing - Current Good Manufacturing Practice, September 2004. 